\title{
Correspondence
}

Cerebrovascular Diseases

Cerebrovasc Dis 2007;24:318

DOI: $10.1159 / 000106519$

\section{Asymptomatic Myocardial Infarction prior to Ischemic Stroke?}

Jesper K. Jensen ${ }^{\text {a }}$, Dan Atar ${ }^{b}$, Hans Mickley ${ }^{\text {a }}$

${ }^{a}$ Department of Cardiology, Odense University Hospital, Odense, Denmark; ${ }^{b}$ Division of Cardiology, Aker University Hospital, University of Oslo, Oslo, Norway

In a recent issue of Cerebrovascular Diseases, Barber et al. [1] attempted to identify the link between sympathetic nervous activity and myocardial cell damage in patients with acute ischemic stroke. They studied 222 consecutive acute ischemic stroke admissions within $24 \mathrm{~h}$ of symptom debut. Troponin I, catecholamines and a 12-lead resting ECG were measured once. Elevated levels of troponin I $(>0.2 \mu \mathrm{g} / \mathrm{l})$ were detected in $20 \%$ of the patients. These patients had higher levels of epinephrine and were more likely to have ECG changes suggestive of acute myocardial infarction (AMI). The authors concluded that their findings were consistent with activation of the sympathetic nervous system leading to myocytolysis.

We applaud the authors for attempting to demonstrate what may well be a valid assumption. The theory of neuromediated myocardial cell damage (due to, at least in part, elevated catecholamines) has been repeatedly proposed for several years mostly in patients with subarachnoid hemorrhage and intracranial bleedings $[2,3]$. However, there are several additional considerations to the authors' conclusions.

Firstly, their analysis is retrospective and when reading their inclusion and exclusion criteria there is no information regarding patients which might have had symptoms of AMI days or hours ahead of the cerebrovascular event $[1,4]$. In this context, it is important to remember that following AMI the incidence of ischemic stroke is markedly increased, particularly during the first 30 days after the cardiac index event [5-7]. Troponin can stay elevated as long as $2(\sim 3)$ weeks after an AMI depending on the size [8]. Therefore the ECG changes and elevated levels of troponin I could be a result of recent AMI which per se can lead to elevated levels of catecholamines. Ischemic heart disease in the elderly may in fact go unnoticed due to absence of symptoms, memory impairment and/or diminished physical activity [9]. Indeed, up to $25 \%$ of AMIs are asymptomatic. This problem may even be worse in patients with stroke due to cognitive and language impairments. The authors demonstrated that, in their study, patients with elevated troponin I were older and the stroke was more severe.

Secondly, troponins can be raised due to a number of other conditions, e.g. renal insufficiency and heart failure [10]. In the study by Barber et al. [1] a higher frequency of patients with elevated levels of troponin I had renal failure, while there is no in- formation on heart failure. Patients with renal failure often suffer from atherosclerotic lesions and, not surprisingly, do often have elevated troponins and catecholamines. Furthermore, heart failure is a known condition causing elevated troponin [10]. Patients with heart failure are at increased risk of suffering an ischemic stroke.

Thirdly, the definition of myocardial infarction relies on the fact that serial, i.e. at least two, measurements of biomarkers (troponin and/or CK-MB) are obtained so that a rise-and-fall pattern - a prerequisite for diagnosis - can be detected [11].

Since the coexistence of coronary artery disease has a strong impact on the long-term prognosis of cerebrovascular patients, those with elevated levels of troponins should be routinely scheduled for further cardiac evaluation in order to identify or rule out any possibly coexisting coronary artery disease. The problem with the neuromediated theory is that the patients will not be evaluated by a cardiologist if elevation of troponin is detected.

\section{References}

1 Barber M, Morton JJ, Macfarlane PW, Barlow N, Roditi G, Stott DJ: Elevated troponin levels are associated with sympathoadrenal activation in acute ischaemic stroke. Cerebrovasc Dis 2006;23:260-266.

2 Oppenheimer SM, Hachinski VC: The cardiac consequences of stroke. Neurol Clin 1992;10:167-176.

3 Khechinashvili G, Asplund K: Electrocardiographic changes in patients with acute stroke: a systematic review. Cerebrovasc Dis 2002;14: 67-76.

4 Barber M, Langhorne P, Rumley A, Lowe GD, Stott DJ: Hemostatic function and progressing ischemic stroke: $\mathrm{D}$-dimer predicts early clinical progression. Stroke 2004;35:1421-1425.

5 Fuster V, Halperin JL: Left ventricular thrombi and cerebral embolism. N Engl J Med 1989;320:392-394.

6 Mooe T, Olofsson BO, Stegmayr B, Eriksson P: Ischemic stroke: impact of a recent myocardial infarction. Stroke 1999;30:997-1001.

7 Witt BJ, Brown RD Jr, Jacobsen SJ, Weston SA, Yawn BP, Roger VL: A community-based study of stroke incidence after myocardial infarction. Ann Intern Med 2005;143:785-792.

8 Katus HA, Remppis A, Scheffold T, Diederich KW, Kuebler W: Intracellular compartmentation of cardiac troponin $\mathrm{T}$ and its release kinetics in patients with reperfused and nonreperfused myocardial infarction. Am J Cardiol 1991;67:1360-1367.

9 Sheifer SE, Gersh BJ, Yanez ND 3rd, Ades PA, Burke GL, Manolio TA: Prevalence, predisposing factors, and prognosis of clinically unrecognized myocardial infarction in the elderly. J Am Coll Cardiol 2000;35: 119-126.

10 Babuin L, Jaffe AS: Troponin: the biomarker of choice for the detection of cardiac injury. CMAJ 2005;173:1191-1202.

11 Myocardial infarction redefined - a consensus document of The Joint European Society of Cardiology/American College of Cardiology Committee for the redefinition of myocardial infarction. Eur Heart J 2000;21:1502-1513.

Jesper K. Jensen

Department of Cardiology, Odense University Hospital

Sdr. Boulevard 29, DK-5000 Odense C

Tel. +45 6017 7420, Fax +4563120854

E-Mail jesperkjensen@dadlnet.dk

\section{KARGER}

Fax +41613061234 E-Mail karger@karger.ch www.karger.com
C 2007 S. Karger AG, Basel

$1015-9770 / 07 / 0243-0318 \$ 23.50 / 0$ 